\title{
La unión de semejanza: fin sobrenatural de la existen- cia. Una meditación antropológica sobre el origen y la finalidad del misticismo, según San Juan de la Cruz
}

\author{
LUCERO GONZÁLEZ SUÁREZ \\ Universidad Nacional Autónoma de México \\ noche_oscura27@yahoo.com.mx
}

\section{Resumen}

El propósito de estas páginas es describir los rasgos esenciales del misticismo como modalidad de la vida fáctica, a partir del análisis de un fenómeno hermenéutico: la obra poética y doctrinal de San Juan de la Cruz. La intención es plantear la pregunta por el origen y el sentido último de la existencia, con el fin de mostrar que la mística destaca por su radicalidad de entre los caminos que conducen al hombre a la plenitud. Esta meditación filosófico-teológica es antropología por su objeto; es fenomenología, por su método; hermenéutica, porque aquello a lo que se dirige la pregunta por el ser del hombre es una construcción textual

Palabras clave: San Juan de la Cruz, Antropología, Dios, mística, existencia.

\section{The union of similarity: supernatural end of existence. An anthropological meditation on the origin and purpose of mysticism, according to saint John of the Cross}

\begin{abstract}
The purpose of these pages is to describe the essential features of mysticism as a modality of factual life, based on an analysis of a hermeneutic phenomenon: the poetry and the doctrine of Saint John of the Cross. The intention is to ask for the source and the ultimate meaning of existence, in order to show that the Mystic stands by its radicalism among the paths that lead to the man in the fullness. This philosophical-theological meditation is anthropology by its object; is phenomenology, its method; hermeneutics, because that what the question is directed by the being of man is a textual construction.
\end{abstract}

Key words: Saint John of the Cross, anthropology, God, mystic, existence.

Doctora en Filosofía por la UNAM. Es Profesora Asociada "C" Tiempo Completo, para la Licenciatura en Filosofía de la FES Acatlán, en el área de Antropología Filosófica. Es autora de los libros iA dónde te escondiste, Amado, y me dejaste con gemido? Una fenomenología hermenéutica del 'Cántico Espiritual B', de San Juan de la Cruz. (aprobado para su publicación por la UIA) y del libro Gocémonos, Amado, y vámonos a ver en tu hermosura. Una meditación fenomenológica sobre la experiencia mística amorosa (aprobado para su publicación por el Centro de Investigación social Avanzada, de Querétaro). Y es co-autora del libro El individuo frente a si mismo. El pensamiento de Sören Kierkegaard (2014).

Recibido: 9/Junio/2016 - Aceptado: 12/Julio/2016 


\section{Introducción}

La pregunta filosófica por excelencia, en la que de acuerdo con Kant se sintetizan las preocupaciones fundamentales de la existencia, alude directamente al ser que nos define: ¿qué es el hombre? A penas hace falta justificar la importancia de dicha interrogante. La necesidad de responder a ella de una forma rigurosa y sistemática surge del doble reconocimiento de que, aun cuando estamos conscientes de que somos, no sabemos quiénes somos. Lejos de ser una verdad clara y distinta, la existencia es un enigma.

No obstante lo anterior, lo cierto es que, como ha puesto de manifiesto la ontología fundamental de Martín Heidegger, en la condición humana hay una tendencia a extraviarse en el mundo a fin de no afrontar el enigma de la existencia. Tendencia en razón de la cual, tan pronto dejamos a un lado la tarea del pensar, nos desentendemos por completo de las preguntas por el origen y por la finalidad última de la existencia, para ocuparnos única y exclusivamente con la resolución de pequeños y triviales problemas de la vida cotidiana.

El costo que el individuo ha de pagar por dicho olvido es una existencia que fluye sin cauce alguno; como agua derramada en una vasija rota, cuyo nivel puede decrecer pero nunca aumentar. El mayor peligro al que estamos expuestos es el olvido de la capacidad para meditar, a solas y en silencio, sobre el ser que somos. A diferencia del pensar calculador, que se limita a planificar la acción productiva, la meditación serena sobre la esencia del ser y de las cosas, permite poner de manifiesto el sentido de su presencia. El problema es que, aun cuando el pensar nos es esencial, cada uno ha de esforzarse por conducir a la consumación la esencia del pensar, puesto que sólo entonces podrá apropiarse de su humanidad.

A fin de que el hombre se apropie de su ser, se impone la necesidad de que atienda a la manifestación de las posibilidades más altas de la existencia y, a partir de la descripción de sus rasgos esenciales, obtenga elementos suficientes para plantear la pregunta ¿qué es el hombre? Más aun, para comprender el ser que somos, tampoco basta describir las determinaciones ontológicas de la existencia; es necesario indagar sobre el origen y el sentido último de ésta.

La importancia vital de dicha investigación deriva del hecho de que sólo cuando se ha comprendido de dónde proviene la existencia cabe inquirir por su sentido último y pronunciarse sobre su plenitud. Lo que, por supuesto, implica reconocer previamente que vivir no es algo que de suyo posea un sentido; en todo caso, de lo que se trata es de vivir bien y de clarificar qué se entiende por tal cosa. Pues es verdad que todo hombre quiere ser feliz, pero la felicidad está lejos de ser una noción unívoca. 
Desde su aparición, la obra de San Juan de la Cruz (=SJC) ha sido objeto de muy variadas consideraciones. Por lo que se refiere al estado de la cuestión, en términos generales y esquemáticos, cabe afirmar que la escuela de interpretación francesa, fundada por Jean Baruzi, se caracteriza por realizar estudios sobre el misticismo, tomando como punto de partida los textos sanjuanistas. Su intención es estudiar el fenómeno místico-religioso a partir de disciplinas como la filosofía, la psicología, la antropología, la filología, etc.

Por su parte, la escuela española se dedica al análisis de la obra sanjuanista en su conjunto. Su interés es desentrañar los principios fundamentales de la doctrina. En la mayoría de los casos, el modelo de interpretación adoptado es de procedencia teológica. Sus representantes más destacados son Eulogio Pacho y Federico Ruiz. Sus limitaciones radican en el compromiso que los intérpretes tienen con la ortodoxia y con la doctrina de la Iglesia. En más de una ocasión, los teólogos que se han ocupado con el estudio de la obra sanjuanista persiguen intereses que van más allá de su comprensión, ya sean de orden pastoral, moral e incluso político. Un claro ejemplo de ello es la descontextualización de la doctrina de SJC acerca de la universalidad de la mística, encaminada a defender la doctrina de las dos vías de salvación.

Asimismo, los estudios hechos por Juan Martín Velasco y José Gómez Caffarena, ocupan un sitio privilegiado en la fenomenología de la religión y de la mística porque al haber contribuido a la exhibición de constantes estructurales en las distintas cosmovisiones religiosas, han advertido la necesidad filosófica de preguntar si hay algo en el ser del hombre que lo haga capaz de lo divino; si la religión y la mística son comportamientos accidentales o, por el contrario, expresan alguna determinación ontológica.

Ahora bien, pese a la abundancia de la literatura filosófico-teológica sobre la obra de SJC, hasta donde yo tengo noticia, el intento de aplicar a la interpretación de la obra poético-doctrinal de SJC las aportaciones de la fenomenología, sin omitir la reflexión sobre la dimensión teológica de las palabras del santo, ha sido una línea de investigación poco desarrollada. Así pues, partiendo del reconocimiento del estado de la cuestión, el propósito de estas páginas es plantear la pregunta por el origen y el sentido último de la unión mística, desde una perspectiva filosófica, libre de compromisos doctrinales, cuya pretensión última es dilucidar la experiencia de Dios de la que SJC ha dado testimonio.

La reflexión filosófico-teológica que aquí desarrollo es antropología por su objeto; es fenomenología, por su método; hermenéutica, porque aquello a lo que se dirige la pregunta por el ser del hombre es un universo textual. El propósito último de esta meditación es arrojar luz sobre la 
respuesta que la mística ofrece a la pregunta: ¿quién es el hombre, delante de Dios?

\section{El poder creador del amor divino: origen de la existencia}

El libro del Génesis nos relata en estos términos la creación del hombre: "Dijo Dios: Hagamos al hombre a nuestra imagen y semejanza" (Gn 1, 26). El pasaje resulta familiar para todos los cristianos. Pero al escucharla, ¿realmente comprendemos que haber sido creados a imagen de Dios supone que la finalidad de nuestra vida es convertirnos en reflejo de su perfección? Para usar una imagen de Santa Teresa de Jesús, podemos decir que ser imagen de Dios significa que cada uno de nosotros es parecido a un espejo o claro cristal donde, de un modo único, habita la presencia de Dios. Cuando el espejo está libre de manchas se parece al río en cuyas aguas aparece reflejada la belleza de lo creado; mas cuando está sucio y opaco es semejante al agua mezclada con fango, porque entonces no se puede distinguir nada de lo que está oculto bajo su superficie, por majestuoso que sea.

El propósito de la actitud ascética es hacer del alma un espejo limpio donde pueda reflejarse en todo su esplendor la presencia de Dios. La finalidad de todas aquellas prácticas y ejercicios que buscan eliminar las inclinaciones equivocadas de la voluntad (que constituyen la raíz de los vicios e imperfecciones morales y espirituales) es que el hombre sea puro para que pueda irradiar la presencia divina, según su peculiar condición. $\mathrm{Al}$ respecto, cada uno podrá juzgar hasta qué punto la totalidad de sus actos cotidianos; de su manera de concebir la vida y de relacionarse con los demás, son reflejo del Dios vivo y verdadero. Lo cierto es que mientras estemos vivos tenemos la posibilidad de limpiarnos; de liberarnos de nuestras malas inclinaciones, para acceder a la experiencia de Dios. Pero la única lejía capaz de devolverle al espejo del alma su pureza es el ascetismo; la determinación de negar todos aquellos hábitos, gustos y contentos que no aproximan al hombre a Dios; sino que ocultan su presencia. Y lo único que puede limpiar la huella profunda que las malas inclinaciones dejan en la voluntad, es la gracia de Dios, que como agua cristalina se derrama en cada hombre con la infusión del Espíritu Santo, cuya fuerza regeneradora libera la voluntad de toda inclinación contraria al amor que Dios es.

La limpieza interior que tienen por fin los ejercicios ascéticos no es solamente una pesada tarea propia de los principiantes espirituales. Es cierto que la principal característica del principiante es la negación de todos aquellos gustos, dependencias y apetitos que eclipsan la presencia interior de Dios. Sin embargo, ni siquiera en los estados más avanzados 
del camino espiritual se puede prescindir de la lejía y del agua ya mencionadas.

Cuando el espejo del alma está manchado por el pecado y por los apetitos voluntarios, por más que Dios siga habitando ese castillo interior que es el alma, el individuo es incapaz de percibir e irradiar su presencia. Ya que cuando el individuo no se da a la tarea de purificar las operaciones de sus potencias, el pensamiento, el deseo y el recuerdo de los bienes finitos a los que se aspira egoístamente son tan fuertes que ocupan por completo el castillo y hacen del Rey que lo habita un prisionero. Por el contrario, cuando el proceso de purificación y limpieza progresa, los intrusos que han usurpado el castillo comienzan a retirarse. Entonces, comienza a relucir la presencia interior de Dios en cada uno, que se adecua a la forma de ser y condición personal, dado que la manera en que la inhabitación de Dios "no opera en el vacío, sino que respeta y tiene en cuenta el propio modo de ser humano" (Graeff, 1970: 70).

Por naturaleza somos imágenes de Dios. Gracias a ello estamos en condiciones de participar de su amor. Sin embargo, depende de nosotros la decisión de limpiarnos o no de todo aquello que empaña la belleza de nuestro ser, a fin de convertirnos en imagen y semejanza suya. Ser semejante a Dios es liberar espacio en nuestras vidas; es echar a un lado todo aquello que estorba nuestra comunicación y comunión con Dios; es comprender la poca importancia que tienen nuestras más preocupaciones comparadas con el fin último de la salvación, a fin de permitirle a Dios habitar en el castillo de nuestra alma.

$\mathrm{Al}$ referirse a la condición creatural del hombre, SJC dice que tanto la existencia como la esencia del hombre son efectos del poder creador de Dios, que expresa y tiene por fin el amor-ágape. El amor-ágape es el principio y el fin al que todo tiende y del que todo procede: es la esencia de Dios, en virtud de la cual crea al hombre.

De acuerdo con la revelación y la experiencia mística, Dios ha creado al hombre por amor y para amar, tomando como modelo a "la Sabiduría suya por quien las crió, que es el Verbo, su Unigénito Hijo" (Cruz, 1994a: canción 5, párrafo 1). A pesar de ser trascendente, Dios es también inmanente al hombre. La razón de lo cual es que la creación no es un acto productor que el Hacedor o el Demiurgo haya realizado fijando la mirada en lo eterno e idéntico para tomarlo como modelo; sino una acto que crea al mundo y al hombre, al palacio y a la esposa, llamándolos a ser desde la nada, a fin de que puedan participar del amor que define la esencia divina, a su modo y según su capacidad. En el Timeo,

Platón habla de "producir", de un "acto de hacer", de una "hechura". El verbo utilizado es poieo; su significado: fabricar, ejecutar, confeccionar; 
crear, producir, en el sentido de engendrar, dar a luz, producir el suelo, hacer nacer, causar; actuar, ser eficaz [...] Pero los libros griegos de la Biblia, y sobre todo el Nuevo Testamento, hablan de otra cosa [...] pues ya no es 'hacer', 'producir', 'demiugar', sino "crear". Esta nueva palabra significa en griego clásico construir casas o ciudades; fundar una colonia; instituir (Pérez, 2002: 130-131).

El modelo para la creación del mundo desde la nada, no es un arquetipo presente en el entendimiento divino ni una forma preexistente que la voluntad de Dios elige por su perfección relativa y que su potencia crea como, por cierto, Leibniz parece pensar. El modelo según el cual ha tenido lugar la creación es Dios mismo en la Persona del Hijo; es el Verbo o la Sabiduría. Al mundo y al hombre, únicamente "la mano del Amado Dios [es decir, del Verbo] pudo hacerlas y criarlas [...] porque, aunque otras muchas cosas hace Dios por mano ajena [...] esta que es criar nunca la hizo ni la hace por otra que por la suya propia" (Cruz, 1994a: canción 5, párrafo 3). Por sí solo, el Verbo hizo todo: "por él se hizo todo, y nada llegó a ser hecho sin él" (Jn 1, 3). Por ser obra del Amado, la creación expresa parcialmente la perfección del Creador, quien "crió todas las cosas con gran facilidad y brevedad y en ellas dejó algún rastro de quien Él era, no sólo dándoles el ser de nada, mas aun dotándolas de innumerables gracias y virtudes, hermoseándolas con admirable orden y dependencia indeficiente que tienen unas de otras" (Cruz, 1994a: canción 5, párrafo 1).

Es, pues, de saber que con sola esta figura de su Hijo miró Dios todas las cosas, que fue darles el ser natural, comunicándoles muchas gracias y dones naturales, haciéndolas acabadas y perfectas [...] Y no solamente les comunicó el ser y gracias naturales mirándolas, como hacemos dicho, mas también con sola esta figura de su Hijo las dejó vestidas de hermosura, comunicándoles el ser sobrenatural; lo cual fue cuando se hizo hombre, ensalzándole en hermosura de Dios y, por consiguiente a todas las criaturas con él, por haberse unido con la naturaleza de todas ellas en el hombre (Cruz, 1994a: canción 5, párrafo 4).

Al decir lo anterior, el poeta místico asume tanto la perspectiva paulina como la joanea y sostiene que si al crear al mundo y al hombre, tomando como modelo al Hijo, Dios ya había dotado de dones a las criaturas, la perfección de lo creado tiene lugar gracias a la encarnación. Por obra de la encarnación, todo aquello que es asumido, es también exaltado. Si el Verbo se hizo carne fue para que el ser finito y carnal que somos, estuviera en condiciones de hacerse Dios por participación. La encarnación no sólo dotó de dignidad al hombre sino que, a través suyo, 
elevó a un estado de mayor perfección al mundo. El texto revelado que resuena en la afirmación del poeta místico es: "y yo, cuando haya sido levantado de la tierra, levantaré a mí todas las cosas" (Jn 12, 32). En la resurrección, cuando Cristo Crucificado asume la forma de Señor exaltado, atrae hacia sí la creación entera. Por lo cual dice el santo: que "en este levantamiento de la encarnación de su Hijo y de la gloria de su resurrección según la carne, no solamente hermoseó el Padre las criaturas en parte, mas podemos decir que las dejó vestidas de hermosura y dignidad" (Cruz, 1994a: canción 5, párrafo 4).

En sí mismas, las criaturas (sobre todo el hombre) son rastros de la perfección del Amado, a través de los cuales se hace manifiesta su existencia. No obstante, en tanto no se haya llevado a cabo la purificación del sentido, el goce en la consideración y posesión de las criaturas constituye un riesgo de alienación. La presencia de las criaturas es un peligro para la voluntad desordenada. Al no considerar que comparadas con el ser de Dios las criaturas son poco menos que nada, la voluntad que toma como criterio de acción el goce egoísta se olvida con facilidad del fin sobrenatural de la existencia. El amor desordenado a lo creado, habitualmente asume la forma de apetito y esclaviza al hombre, incapacitándolo para la experiencia de Dios.

Ahora bien, entre la manera en que SJC habla de las criaturas en la Subida del Monte Carmelo y el modo en que lo hace en el Cántico Espiritual B hay una gran diferencia. Ello obedece no a que el objeto sea distinto, sino a la perspectiva desde la cual es contemplado: como fin en sí mismo y como huella de la presencia divina, respectivamente. Cuando en la Subida del Monte Carmelo se refiere a la necesidad de la purificación activa del sentido, SJC sobre todo enfatiza la distancia infinita que hay entre las criaturas y el Creador, "Porque ¿qué tiene que ver criatura con Criador, sensual con espiritual, visible con invisible, temporal con eterno?" (Cruz, 1994d: libro I, capítulo 6, párrafo 1). El santo sostiene que, consideradas sin relación al principio del que proceden, el ser de las criaturas carece de sustento alguno. De ahí que al ser comparadas con el ser de Dios, haya que concluir que las criaturas no son más que esas nadas que seducen la voluntad y nublan el entendimiento. No obstante, hay que recordar que el origen de la distancia es el pecado, que impide al hombre la consideración de las criaturas en Dios.

Por su parte, el Cántico Espiritual B celebra el reencuentro con la creación del alma que ya ha pasado por las purificaciones activas y pasivas del sentido y del espíritu. Para la esposa, las criaturas son mediaciones de la presencia divina; no fines en sí mismos, capaces de sojuzgar la voluntad del hombre hasta el punto de provocar que se olvide de Dios por ir en busca de su posesión. Tan pronto aparta el gozo de los bienes 
finitos, el alma “Adquiere más gozo y recreación en las criaturas con el desapropio de ellas" (Cruz, 1994d: libro III, capítulo 20, párrafo 2).

El poder creador del amor que Dios es, constituye el origen de la creación del mundo y del hombre. Ambos son huellas o rastros de la perfección divina; son obras del Amado, que manifiestan su gloria desde una perspectiva. Pero mientras que los entes naturales reflejan con su sola presencia el ser del Creador; el hombre está llamado a purificarse de todos aquellos apetitos, asimientos, vicios e imperfecciones que opacan la presencia de Dios en su interior.

\section{La unión de semejanza amorosa con el Esposo Cristo: fin sobre- natural de la existencia}

De acuerdo con la revelación, “[Dios] nos predestinó para adopción como hijos para sí mediante Jesucristo, conforme al beneplácito de su voluntad, para alabanza de la gloria de su gracia" (Ef 1, 5-6). La gloria de la gracia de Dios -que San Pablo llama "riquezas de su gracia por su bondad para con nosotros en Cristo Jesús" (Ef 2, 7)- es el clímax de la revelación. Y el propósito de la pre-destinación, de aquello para lo cual Dios destinó a todo hombre al crearlo, es la igualdad de semejanza con Cristo.

Aceptado lo anterior, es preciso distinguir entre aquello que se conoce por la autoridad de la revelación y aquello que se comprende a través de la experiencia. Gracias a la revelación, sabemos que Dios nos creó por amor y para amar. Pero, ¿cómo accedemos a dicha experiencia? Todo apunta a que no hay deducción alguna capaz de conducirnos a la esencia amorosa de Dios. La única manera de que el hombre caiga en la cuenta de "la gran deuda que a Dios debe en haberlo redimido solamente por sí mismo, la debe todo el amor de su voluntad" (Cruz, 1994a: canción 1, párrafo 1), es el encuentro con el Amado, cuya presencia seduce y enamora, suscitando el movimiento de la conversión.

Cada uno de nosotros puede escuchar excelentes disertaciones y discursos edificantes sobre el amor divino; pero sólo el amor que Dios es tiene el poder de manifestarse a sí mismo, desde sí mismo. Sólo la irrupción de la presencia divina en la vida de cada hombre tiene la potencia para interpelarlo y hacerle comprender que su vida no es en fin en sí mismo, sino que está ordenada a Dios. Es decir, que la plenitud de la vida humana no se alcanza mediante un proceso de conquista de la autonomía y afirmación de la voluntad; sino mediante la negación de todos aquellos vicios, imperfecciones, apetitos y asimientos que alejan al hombre de Dios. 
A tenor de lo que el poeta místico declara en el comienzo de Cántico Espiritual B,

El origen de la contrición que padece el converso ciertamente es el reconocimiento de su dependencia respecto del Amado; mas la suya es una dependencia amorosa respecto de quien por amor se encarnó, padeció y se dejó crucificar, para ofrecerle la vida eterna. A pesar de lo cual, lejos de corresponder a tal deuda amorosa, hasta antes de «caer en la cuenta» del fin sobrenatural para el cual ha sido creado, el existente no ha hecho más que vivir para sí o, en el mejor de los casos, se ha conformado con el ejercicio del amor interesado (González, 2012: 68).

El poeta místico no habla de una deuda metafísica sino amorosa, para dar a entender que quien tiene la experiencia de encuentro con Dios en Cristo, ante todo, se sabe desbordado por el poder creador y redentor del amor divino. Aquello que el converso desea es corresponder a ese amor espontáneo, inmerecido, universal e incondicional que Dios le ha otorgado, por principio. Desde luego, si el converso desea corresponder al amor divino no es porque piense que ello le aporte algo a Dios. El amor místico es respuesta espontánea al llamado originario del amor divino. En el orden sobrenatural, conocer es ser. Lo cual significa que, para el místico, saberse amado es no sólo acoger pasivamente una experiencia, sino responder a ella amando, a fin de hacer fructificar el don recibido.

Luego de recibir la visita del Amado, cuyo fin es inflamar la voluntad en el amor divino, a fin de que el alma-amada cobre la fuerza necesaria para negar sus apetitos, gustos y aficiones, ésta reconoce su vocación esencial: comprende que "para que pudiese venir a esto la crió a su imagen y semejanza” (Cruz, 1994a: canción 39, párrafo 4) y la redimió. Esto es, que al crear y redimir al hombre, Dios lo pre-destinación o lo destinó por principio a participación de la vida eterna, que consiste en amar y conocer a Dios como Él mismo se conoce y se ama en las Personas de la Santísima Trinidad y ama al hombre: de una forma ilimitada, incondicionada y universal.

No obstante lo anterior, la relación de unión amorosa con Dios no puede darse sin más. No basta que el hombre quiera estar en la presencia de Dios y presente sus quejas de amor para que se realice la unión de semejanza amorosa. Para que ello pueda tener lugar, deben ser eliminados los obstáculos que impiden la unión. Por eso son necesarias tanto la purificación activa y pasiva del sentido como la del espíritu.

El principio fundamental de la antropología de SJC es que el hombre es imagen de Dios y está llamado a ser semejanza de Jesús. Pero dicha transformación reclama como condición de posibilidad de un largo y 
arduo camino de perfeccionamiento, simbolizado por la subida del Monte Carmelo. La mística es ese proceso a través del cual se realiza plenamente la semejanza a la que el hombre está llamado. En dicho proceso juega un papel decisivo la cooperación del hombre, que hace cuanto está en su poder para disponerse favorablemente al encuentro con Dios mediante la negación de sus tendencias desordenadas. Pero más importante aún es la gracia divina que, obrando pasivamente, purifica la raíz de las imperfecciones del hombre, a fin de que éste pueda acoger la noticia sobrenatural de la fe, a la que el santo define como el único medio proporcionado al fin sobrenatural de la deificación.

La mística sanjuanista establece una relación entre antropología y cristología. "Sin la persona de Cristo ni el sistema sanjuanista se tiene en pie ni el sendero de las tres nadas conduce a ningún lugar" (Molina, 1991: 24). Jesús es el modelo a imitar para el hombre. En Cristo Jesús, Dios se encarnó y se hizo hombre para que el hombre se hiciera Dios por participación. Desde la eternidad, el Padre, "a los que de antemano conoció, también los predestinó a reproducir la imagen de su Hijo, para que fuera él el primogénito entre muchos hermanos; y a los que predestinó, a ésos también los llamó” (Rom 8, 29-30).

El sentido último de la vida humana es asemejarse a Cristo. Lo que equivale a estar dispuesto para atender al llamado: "Sed, pues, imitadores de Dios, como hijos queridos, y vivid en el amor como Cristo os amó y se entregó por nosotros como oblación y víctima de suave aroma" (Ef 5, 1-2). Ser cristiano es hacer propia la cruz de Cristo, tal como ésta se configura en nuestras propias circunstancias: en la aceptación de nuestras limitaciones y en el reconocimiento de que en la más honda desesperación, en la soledad y el dolor, brilla la esperanza de que Dios no nos abandona. Ser cristiano es saber que al participar de la muerte de Cristo, participamos también de su resurrección.

En todas sus obras, refiriéndose al amor que se manifestó en la cruz de Cristo, SJC repite incesantemente que "Al fin, para este fin de amor fuimos criados" (Cruz, 1994a, canción 2, párrafo 32). La evidencia fenomenológica de esa destinación esencial del hombre a la unión con Dios es la tendencia natural, no reflexiva, que provoca en el individuo el deseo de Dios. Lo que el santo da a entender cuando se refiere a la "igualdad de amor con Dios, que natural y sobrenaturalmente apetece" (Cruz, 1994a, canción 38, párrafo 3).

¿A qué se refiere el santo con apetito natural y sobrenatural de Dios? Él no lo aclara. Sin embargo, considero que es posible encontrar una indicación sobre el modo en que habría que constatar dicha pregunta, en las descripciones que ha hecho del modo de vida de los espirituales, a lo largo de cada una de las fases del proceso místico. Con el propósito de 
comprender el sentido, el origen y la finalidad de dicho apetito, es preciso atender al tipo de relación que el espiritual entabla con Dios.

En todas sus obras, cuando SJC se ocupa con la reflexión sobre el ser del hombre, lo hace a la luz del fin sobrenatural de la existencia. A diferencia de otros pensadores, no repara siquiera en el modo de vida que distingue al hombre que vive apartado de Dios del místico. La razón de lo cual es, a mi entender, que los lectores a quienes están destinadas sus guías espirituales, por más bajo que sea su grado de perfección, están convencidos de que la unión con Dios es la finalidad de la existencia. En otro sentido, la aparente evidencia de la que parte SJC acerca de la importancia concedida por todos los hombres a la búsqueda de la salvación puede explicarse por otras dos razones. La primera tiene que ver con el espíritu de la época: tan natural era para un hombre de su tiempo preocuparse seriamente por su salvación: como ahora lo es, para que quienes han crecido en el seno de las sociedades secularizadas, ser indiferentes al problema de Dios. La otra razón es que, como cualquier otro amante, SJC no puede siquiera comprender cómo es que algunas personas alguien pueden ser del todo indiferentes al amor divino, siendo que Dios constantemente sale a su encuentro para enamorarlos.

Lo que a SJC le interesa no es explicar por qué el hombre siente ese apetito natural y sobrenatural de Dios, sino por qué dicho apetito está más inflamado en unos sujetos que en otros. En segundo lugar, le parece importante dar cuenta de que aun cuando tal inflamación es indispensable en los comienzos del proceso místico, las "ansias en amores inflamadas" no son un medio apropiado para el fin de la unión de semejanza amorosa con el Esposo.

Ahora bien, dado que nosotros no habitamos en el mundo históricocultural de SJC y desafortunadamente tampoco compartimos su experiencia, para comprender el significado del apetito "natural y sobrenatural" de Dios tenemos que emprender una meditación sobre la experiencia mística, a partir del testimonio que nos ha legado. La tarea filosóficoteológica al respecto consiste en pensar sobre aquello que quedó sin pensar; que quedó oculto porque para el santo era evidente, pero para nosotros ya no lo es.

Con el propósito de esclarecer la cuestión sobre el origen del deseo de lo divino, considero apropiado señalar lo siguiente. Tan pronto se repara en la experiencia, es fácil constatar que el rasgo esencial que nos define es el deseo infinito de sentido infinito: sin importar nuestra finitud y la limitación de nuestro poder ser, anhelamos siempre lo infinito, infinitamente. Ahora bien, ese deseo infinito que somos puede orientarse tanto a lo infinito como a lo finito. Las posibilidades fundamentales del existente son: 1. Empeñarse en desear finitamente lo finito. 2. Desear 
finitamente lo infinito. 3. Desear finitamente lo infinito. 4. Desear infinitamente lo infinito.

La primera de ellas expresa un esfuerzo vano por reducir el alcance del deseo, a fin de que se ajuste a la finitud del mundo. La intención es superar la infelicidad que nos provoca no disponer de un sentido infinito que dirija nuestra vida diaria, acortando el alcance de nuestros proyectos. Quien así piensa, asume que sólo existe la finitud, y trata de contentarse con ella; de saciar su sed de sentido con la posesión y el goce efímero de lo finito.

La segunda posibilidad, que consiste en desear infinitamente lo finito, se concreta en la vida que se deja arrastrar de un lado a otro, sin tener nunca paz ni serenidad, por las pasiones naturales ya referidas: "gozo, esperanza, temor y dolor” (Cruz, 1994d: libro I, capítulo 13, párrafo 5). Tal es el modo de vida de quien está dominado por sus apetitos y agobiado por todos los daños negativos de los que SJC habla en el primer libro de la Subida del Monte Carmelo.

La tercera posibilidad consiste en desear infinitamente lo finito. Una de las mayores aportaciones de la mística es haber dejado en claro que la única realidad infinita es Dios, porque su ser trascendente rebasa las limitaciones de los entes. Quien comprende lo anterior, cae en la cuenta de que ese deseo natural de sentido infinito sólo puede alcanzar su satisfacción cuando se dirige al "objeto" que le es propio: Dios. Sin embargo, quien elabora dicho razonamiento olvida que por sus propios medios, sólo puede acceder a la experiencia finita de la infinitud divina. Lo que equivale al deseo infinito de lo finito: no porque el ser de Dios sea finito, sino porque, cuando el hombre intenta representárselo a través de las operaciones naturales de sus potencias (entendimiento, voluntad y memoria), rebaja el ser de Dios, es decir, lo despoja de su dimensión sobrenatural, a la que sólo tiene acceso la fe sobrenatural infusa. Quien busca a Dios por sus propios medios da cuenta del deseo natural que habita en todo hombre. Deseo que, sin embargo, no es un medio adecuado para la unión a la que el hombre aspira.

Finalmente, la cuarta posibilidad alude a la vida mística. Místico es quien se vale de medios proporcionados a la infinitud de lo divino y, por tanto, no sólo reconoce en su voluntad el deseo natural de Dios, sino el deseo sobrenatural de su presencia, cuyo fundamento ontológico es la presencia de Dios en el ser del hombre.

Cuando el espiritual no ha transitado todavía de la meditación a la contemplación, ni le ha sido infundido el hábito y el acto de las virtudes sobrenaturales, su deseo de Dios es natural: la fuerza con la que se dirige hacia Él surge de su condición humana. Pero cuando las operaciones de sus potencias han quedado transformadas por la infusión de la gracia, 
que muda las primeras de humanas e imperfectas en divinas por participación y perfectas, el deseo que dirige su voluntad hacia Dios es acorde al ser de Dios ${ }^{1}$.

De acuerdo con la antropología mística de SJC, la presencia de Dios en el hombre se manifiesta como llamado amoroso que lo invita a abandonar cualquier otro amor para corresponder al amor divino. Aquello a lo que Dios convoca al hombre es a que se retire del mundo y juzgue en su justa dimensión la importancia de los bienes mundanos, de modo que el deseo de posesión de estos últimos no le haga olvidar que Dios es el sumo bien y que la unión amorosa con Cristo es el fin de la vida humana. Puesto que para hallar la presencia escondida de Dios "conviene salir de todas las cosas según la afección y voluntad y entrarse en sumo recogimiento dentro de sí misma" (Cruz, 1994a: canción 1, párrafo 6). Salir es abandonar, dejar a un lado el cuidado y afecto de aquello a lo que anteriormente se estaba apegado. El abandono espiritual es dejar el cuidado de sí mismo y del mundo para concentrase en la búsqueda de Dios: no a través del desprecio del mundo y de sí, sino del desapego. Superar el amor egoísta a uno mismo por amor a Cristo es asumir la responsabilidad derivada de saber que "el reino de Dios está dentro de vosotros" (Lc 17, 21).

Para explicar la dimensión natural de esa salida, que hace al hombre abandonar el mundo y el cuidado de sí para salir corriendo en pos de las huellas del Esposo, SJC sostiene que el alma tiende hacia Dios de modo semejante a la manera en que el movimiento natural de la piedra la dirige hacia el centro de la Tierra. La imagen es de una claridad notable. Lo que da entender es que, por naturaleza, el movimiento de la voluntad apunta hacia Dios. Sin embargo, tal comparación puede inducir una falsa interpretación del centro del alma, en contra de la cual SJC busca precavernos. El error consiste en pensar que así como el centro de la tierra es un lugar, el centro del alma es una 'región', una 'parte' de una substancia, donde se halla la presencia de una entidad suprema: Dios.

Desde mi interpretación, el centro del alma es una posibilidad de la existencia: así como la piedra puede estar o no en su elemento, según encuentre algún tipo de resistencia o no; el hombre puede dirigir su voluntad y orientar sus acciones teniendo como finalidad la unión de semejanza con Dios u olvidándose de ella. Tanto en su elemento como fuera de él, la piedra y el hombre siguen siendo lo que son. Pero al no realizar el movimiento que corresponde a su ser, ambas están fuera de lugar y, por tanto, adoptan un modo de ser impropio, que en el caso del hombre

1 La necesidad de las purgaciones pasivas de la noche oscura proviene de que sólo a través de éstas el hombre recibe el hábito y el acto infuso de dichas virtudes.

VERITAS, No 35 (Septiembre 2016) 
origina la insatisfacción que distingue a la existencia de quienes no participan de la experiencia de Dios.

De acuerdo con Miroslaw Kiwka, en los escritos sanjuanistas, "la pregunta por el ser del hombre tiene la finalidad de explicar los principios que, en último término, deciden que el hombre obre, conozca y ame de una determinada manera" (Kiwka, 2004: 2). El hombre adopta un modo de ser impropio o superficial cuando todavía no ha descendido al centro de su alma y habita en la periferia o en el estrato más exterior de ésta. Es decir, cuando tiene la voluntad dirigida en una dirección contraria a Dios. Quien vive apartado de Dios tiene la mirada extraviada en los bienes finitos que le salen al paso. Su superficialidad surge de que, embelesado por el espectáculo de la belleza finita, va perdiendo la fuerza para mirarse a sí mismo y descubrir en su ser la huella de Aquel que por amor y para amar lo ha creado. Por el contrario, el hombre interior es aquel que ha sabido esconderse en sí mismo para descubrir, a solas y en silencio, la presencia de Dios de su alma, en el más profundo centro. Tal es el hombre que, haciendo propias las palabras de San Agustín, confiesa: "os buscaba, Dios mío, con los ojos y demás sentidos de mi cuerpo, y no con la potencia intelectiva, en que Vos quisisteis que me distinguiese y aventajase a los irracionales; siendo así que Vos estabais más dentro de mí que lo más interior que hay en mí mismo, y más elevado y superior que lo más elevado y sumo de mi alma” (Agustín, 2011, libro 3, capítulo 6).

Para SJC, el amor es la inclinación del alma; la fuerza y virtud para ir a Dios. Ser hombre es estar abierto a Dios; experimentar el deseo natural y sobrenatural de su presencia. Si el hombre desea natural y sobrenaturalmente la presencia de Dios es porque, en razón de su ser creado, participa de la presencia esencial de Dios, que es principio de su creación y conservación. Dicha presencia es el origen de la actitud místico-religiosa. Ya que "así como el hombre no podría sentir necesidad de agua, no podría sentir sed, si no existiese agua dentro de sí como algo connatural a su propio organismo, así la inquietud y la búsqueda humana de lo Absoluto presupone también la experiencia [...] de la presencia del Absoluto en el hombre" (Ross, 2007: 9).

El deseo de Dios no tiene la forma del anhelo de algo distinto del hombre. Toda vez que, en su realidad más propia y esencial, el hombre es Dios por participación, el deseo de arribar a la unión de semejanza amorosa coincide con el deseo de ser sí mismo. En el contexto del misticismo, la afirmación de la existencia, paradójicamente, tiene la forma de la negación de sí mismo.

El místico, mejor que ningún otro hombre, sabe que el amor-ágape no sólo es la esencia divina y la esencia del hombre que se ha hecho semejante a Dios. Más aun, sabe que el amor perfecto es la fuerza que hace 
posible el conocimiento sobrenatural de Dios. Una fuerza que, por su propia naturaleza, carece de límite alguno y que nunca se detiene ni se agota, porque surge y está dirigida a la infinitud de Dios. Por lo cual, refiriéndose al espiritual que ha llegado al matrimonio espiritual, dice SJC que, "aunque esté en su centro, que es Dios, por gracia y por la comunicación suya que con ella tiene, por cuanto todavía tiene movimiento y fuerza para ir a más y no está satisfecha" (Cruz, 1994a, canción 1, párrafo 12).

El amor-ágape es hábito y acto y, por lo mismo, no puede permanecer ocioso. Lo que explica que a cada uno de sus avances corresponda un nuevo modo de experiencia de Dios y un nuevo modo de existencia humana. Para dar a entender lo anterior, SJC sostiene que el amor tiene grados, porque "muchas mansiones que hay en la casa del Padre" (Jn 14, 2). Según sea el grado de amor a Dios será el grado de participación en su vida eterna, es decir, el modo en que las Personas de la Santísima Trinidad moran en cada hombre, en cumplimiento de la promesa "vendremos a él y haremos morada en él" (Jn 14, 23).

La experiencia de Dios no debe confundirse con la representación de un objeto, a través de alguna operación del entendimiento, de la voluntad o de la memoria. El encuentro con la realidad sobrenatural y trascendente de Dios no es el resultado de un acto de intelección, del deseo, ni de la rememoración de un objeto llamado Dios, donde se mantienen tanto la distancia como la diferencia entre el sujeto que desea y la realidad pensada, deseada o recordada. Puesto que la experiencia de su ser sólo puede tener lugar en el medio de la fe sobrenatural, el conocimiento de Dios es participación en su vida. Para el místico, conocer a Dios es ser Dios por participación. El místico “es Dios por participación, aunque es verdad que su ser naturalmente tan distinto se le tiene del de Dios como antes, aunque esté transformado" (Cruz, 1994d: libro II, capítulo 5, párrafo 7).

Quien es elevado por la gracia de Dios al matrimonio espiritual, se transforma en la Santísima Trinidad. En tan dichoso estado, "por modo comunicado y participado, obrándolo Dios en la misma alma [...] es estar transformada en las tres Personas en potencia, sabiduría y amor, y en esto es semejante el alma a Dios, y para que pudiera venir a esto la crió a su imagen y semejanza" (Cruz, 1994a: canción 39, párrafo 4).

El fin de la existencia es la deificación, que consiste en la participación de las facultades o potencias del alma (entendimiento, voluntad y memoria) de la actividad divina. Transformación gracias a la cual, el entendimiento recibe la inteligencia natural y sobrenatural de Dios (razón/ fe oscura). La voluntad, recibe la comunicación e inflamación amorosa del amor divino. Mientras que la memoria redunda en la noticia 
amorosa por la que el hombre, a un mismo tiempo, sabe y gusta, la presencia divina.

Las virtudes teologales sobrenaturales, cuya infusión lleva aparejada la de las virtudes morales, son el único medio proporcionado para la unión con Dios.

La Fe nos hace capaces de conocer y juzgar la realidad como Jesús la conoce y la juzga; la Esperanza orienta todos nuestros deseos a donde Jesús nos espera, en la gloria del Padre; la Caridad nos hace amar lo que Jesús ama y como Él lo ama. En otras palabras la Fe no es otra cosa que "Dios que piensa en nosotros"; la Esperanza es "Dios que desea en nosotros"; la Caridad es "Dios que ama en nosotros" (Albaní \& Astrua, 1992: 18).

No es una sola de sus facultades ni todas ellas juntas las que gozan de la experiencia de Dios, sino el hombre como ser unitario. El poeta místico es muy tajante al sostener que la unidad del supuesto humano es la razón por la cual el desorden de una de las porciones del ser del hombre, repercute en la otra. La necesidad de las purgaciones activas y pasivas tiene por causa la "comunicación que hay de una parte a la otra" (Cruz, 1994c: libro II, capítulo 1, párrafo 1).

La finalidad última del proceso místico es la armonización del ser del hombre. Cuando se ha alcanzado la armonía entre las dos porciones, es como si estuviesen "comiendo cada una a su manera de un mismo manjar espiritual en un mismo plato de un solo supuesto y sujeto" (Cruz, 1994c: libro II, capítulo 3, párrafo 1). Las purificaciones activas y pasivas, del sentido y del espíritu no tienen otro propósito que liberar de sus imperfecciones las "dos porciones en que se encierra toda la armonía de las potencias y sentido del hombre, a al cual armonía llama aquí montaña" (Cruz, 1994a: canción 16, párrafo 10).

De acuerdo con SJC, la necesidad de la noche oscura radica en que la noche del sentido "más se puede y debe llamar cierta reformación y enfrenamiento del apetito que purgación. La causa es porque todas las imperfecciones y desórdenes de la parte sensitiva tienen su fuerza y raíz en el espíritu, donde se sujetan todos los hábitos buenos y malos, y así, hasta que éstos se purgan, las rebeliones y siniestros del sentido no se pueden bien purgar" (Cruz, 1994c: libro II, capítulo 3, párrafo 1). Afirmación a través de la cual se torna manifiesto que la experiencia de Dios afecta y transforma la totalidad de la existencia. 


\section{La mística: camino de plenitud}

Para la mística sanjuanista, comprender al hombre es dar cuenta de su dimensión teologal. A diferencia de otro tipo de visiones, la antropología mística cristiana sostiene que sólo cuando el hombre renuncia al afán de afirmarse a sí mismo y de reconocer la inmanencia como último horizonte de sentido, está en condiciones de realizar el movimiento vital que lo conduce a la plenitud. A saber, el descentramiento respecto de sí mismo y del mundo, al que también cabe comprender como desapego y negación.

La fuerza de donde procede el movimiento por obra del cual el hombre se descentra; es decir, deja de colocar su cuidado en el mundo que habita y en sí mismo para abrirse a la experiencia de Dios, es el amorágape que mora en su interior. El cual, como ya se ha dicho, se identifica con la presencia esencial de Dios en aquel a quien creó teniendo como modelo al Hijo y en comunión con Él: el hombre.

La enseñanza fundamental de la antropología mística sanjuanista es que el hombre no posee su propio acto de ser, puesto que tiene la razón última de su existencia en Dios. Lo anterior, evidentemente, no significa que no sea libre o que carezca de responsabilidad moral; sino que se ha creado a sí mismo. En tanto que creatura, el hombre posee su origen y la razón última de sus existencia en Dios. Tal es la idea que San Agustín presenta en el libro primero de sus Confesiones: Dios nos ha creado por amor y para amar. La unión de semejanza amorosa, que consiste en amar a Dios y al prójimo como Dios se ama a así mismo, es el fin sobrenatural de la existencia. Dios nos creó para unirnos consigo y, en tanto no alcancemos la unión mística, viviremos aspirando a esa dicha inefable.

Con relación a todo lo creado, Dios es el principio del que procede la vida. Un principio cuya realidad sobrenatural, impide identificarlo (como hace la teodicea) con un ente de mayor grado y jerarquía, del que dependen todos los demás pero que, al final de cuentas, comparte con ellos una misma condición de ser.

Dios está en el hombre como su fundamento, pero no se reduce ni se confunde con él. La mística sabe que definir a Dios como principio y fundamento metafísico del hombre y de las cosas instrumentaliza a Dios, al tiempo que degrada su misterio y trascendencia. Un Dios cuyo ser puede ser definido en función de sus efectos, no alberga ya misterio alguno; se ha vuelto comprensible pero, a costa de ello, ha dejado de ser Dios para convertirse en la piedra de toque de un sistema que busca explicar la realidad. Ante el peligro de definir el ser de Dios y pensar que su ser se identifica con alguna de las noticias que naturalmente podemos alcanzar a través de nuestras facultades (entendimiento, voluntad y me- 
moria), SJC nos advierte que nada de eso puede ser Dios, porque ninguna conveniencia ni semejanza hay entre lo natural y lo sobrenatural.

A lo largo del proceso místico, no sólo se transforma la representación que el hombre tiene de Dios, sino también la concepción que tiene de sí mismo y de la naturaleza. Pero eso no significa que Dios esté sujeto a transformación alguna o que pase de ser un ente a convertirse en un acontecimiento; quiere decir que es la revelación de su misterio acaece conforme a la capacidad y grado de pureza del alma. "Porque es de saber que el mismo fuego del amor que después se une al alma glorificándola es el que antes la embiste purgándola" (Cruz, 1994b: canción 1, párrafo 19). Dios es siempre "fuego consumidor [...] fuego de amor [...] Pero a cada una abraza y absorbe como la halla dispuesta" (Cruz, 1994b: canción 2, párrafo 2). Y en los comienzos del itinerario espiritual ese fuego tiene la función de purificar; mientras que sobre todo después del desposorio, su noticia es causa de intenso deleite.

Ciertamente, Dios es principio y fundamento de la vida; pero es un principio que no requiere de otro principio, cuya realidad trascendente y misteriosa no puede ser abarcada por el discurso natural de la metafísica ni de la teodicea. Lo único que puede decir de Dios sin socavar su trascendencia es aquello que nos ha sido revelado y que ha quedado recogido en los testimonios de las Sagradas Escrituras y de los místicos. A saber, que a la luz de la ciencia sabrosa y sobrenatural de la fe, que para el entendimiento es noche oscura, Dios es amor-ágape.

La segunda enseñanza de la mística sanjuanista es que el hombre tiene el origen de su existencia en Dios, quien habita en él conservándole el ser. Dicha presencia escondida constituye la condición de posibilidad de la apertura del hombre al encuentro con Dios. El principio (entendido como aquello de donde algo procede) de la experiencia de Dios es la estructura de nuestro ser: creados por amor y para amar, albergamos en nosotros mismos la huella del amor originario que Dios es $\mathrm{y}$, tendemos hacia él natural y sobrenaturalmente. El hombre, de acuerdo con SJC, es "por naturaleza y gracia, un ser de deseo y espíritu abierto hacia el infinito y eterno Dios" (Haas, 2009: 85-86), por lo cual sostiene que "el amor tiene la razón de fin" (Cruz, 1994a: canción 32, párrafo 6).

La idea de la divinización tiene su origen primero en la afirmación de que el hombre ha sido creado a imagen y semejanza de Dios, "según un proceso dinámico que debe concluir con la visión de Dios, cuando "seamos semejantes a él" (1 Jon 3, 2). Este don de "la vida eterna", esta "participación en la naturaleza divina" (2 Pe 1,14) es una adopción filial que hace de nosotros Hijos en el Hijo" (Sesboüé, 1997: 127).

La mística es un camino que conduce a la trascendencia; un itinerario de búsqueda, nacido de la raíz de nuestro ser, que no va desde "un lugar 
donde Dios no está a otro en el que Él esté, sino de una situación [existencial] en la que el sujeto no sabe que está, a otra en la que descubre que ya estaba allí" (Ross, 2007: 48). El proceso místico tiene por intención última disponer al espiritual para que "escuche personalmente el testimonio de la Presencia en su interior y en su vida y consienta a esa Presencia descentrándose en el movimiento de confianza absoluta" (Ross, 2007: 8). Ahora bien, para evitar malos entendidos, no hay que olvidar que "'Experiencia de Dios' no consistirá en hacer a Dios objeto de ningún acto nuestro, sino en tomar consciencia de su presencia que nos precede haciéndonos ser y dándosenos a conocer en la medida en que lo reconozcamos como nuestro fundamento y origen" (Martín, 2009: 76).

Si aceptamos que esa presencia está dada en todos los hombres, la pregunta es ¿por qué hay quienes no se percatan de ella o bien, la rechazan? ¿Por qué, si la mística es la vocación a la que están llamados todos los hombres, sólo una pequeña parte de ellos logra acceder a la unión de semejanza amorosa con el Esposo Cristo? Primero, porque esa presencia tiene lugar "del alma en el más profundo centro", pero el hombre puede instalarse en formas de existencia que le impiden llegar a esos niveles de profundidad. De ahí que la experiencia de Dios, que tiene en su presencia en el hombre su fundamento ontológico, "requiera además presupuestos, predisposiciones o preámbulos existenciales que consisten en formas de vida compatibles con esa Presencia y su reconocimiento por el hombre" (Martín, 2009: 79).

Como señala Federico Ruiz, por poco que se repare en la cotidianidad de la existencia, habrá que aceptar que "El equilibrio humano dejado a su espontaneidad se inclina hacia el sentido" (Ruiz, 1968: 309). Lo cual significa que aun cuando el hombre está llamado a ser Dios por participación, ello no significa que la transformación se dé sin más, de modo que baste esperar a que el tiempo transcurra para que el movimiento del descentramiento tenga lugar; para ello es necesario un proceso mistagógico.

Nuestra condición de seres encarnados pone de manifiesto que en nosotros no sólo hay una tendencia a la unión con el ser invisible e infinito de Dios; sino también, una inclinación natural a extraviarnos en aquello que los sentidos, tanto externos como internos, nos ofrecen como lo más inmediato: las criaturas. Quien pone su amor y cuidado en las criaturas, se hace uno con ellas. Puesto que el amor tiene la capacidad de igualar al que ama y el objeto amado. Por lo cual se denomina mundano al hombre que ama el mundo. Aun cuando en sí mismas las criaturas son bellas, graciosas y buenas, el amor a ellas obstaculiza la búsqueda de la presencia divina. El hombre que orienta su deseo infinito de sentido in- 
finito hacia los bienes finitos, se engaña pensando que la variedad de lo finito y la infinitud son sinónimos. De donde se deriva el equivocado afán de querer arrancarle a las criaturas, un sentido infinito que sólo el amor infinito que Dios es nos puede otorgar.

Por otro lado, quien sólo desarrolla su habilidad natural, incluso cuando pretende elevarse a Dios, convierte a Éste en criatura, por cuanto se vale de medios proporcionados a su ser y confunde a Dios con aquello que sus potencias naturales alcanzan a comprender. Pero, como ha dicho SJC, "ninguna noticia ni aprehensión sobrenatural en este mortal estado le puede servir [al hombre] de medio próximo para la alta unión de amor con Dios, porque todo lo que puede entender el entendimiento y gustar la voluntad y fabricar la imaginación es muy disímil y desproporcionado (como habemos dicho) a Dios" (Cruz, 1994d: libro 2, capítulo 8, párrafo 5).

\section{Conclusiones}

La manera en la que respondemos a la pregunta sobre el ser que somos, determina la forma en que vivimos. Por lo cual cabe afirmar que tanto la antropología filosófica como la teológica son saberes que poseen una dimensión existencial. La pregunta central de la antropología, en cualquiera de sus dos modalidades, es: ¿qué es el hombre? Al respecto, el mensaje radical de SJC es que el hombre es un modo de ser finito de Dios. Místico es aquel en quien la presencia de Dios se transparenta de un modo único, a través de las obras del amor perfecto. La motivación de la mistagogía sanjuanista es que el hombre espiritual entienda

el misterio de la puerta y del camino de Cristo para unirse con Dios, y sepa que cuanto más se anihilase por Dios según estas dos partes, sensitiva y espiritual, tanto más se une a Dios y tanto mayor obra hace. Y cuando viniere a quedar resuelto en nada, que sería la suma humildad, quedará hecha la unión espiritual entre el alma y Dios, que es el mayor y más alto estado a que en esta vida se puede llegar (Cruz, 1994d: libro 2, capítulo 7, párrafo 11).

El para qué de la vida aparece sólo al final de la investigación sobre el ser que somos. Sin embargo, es lo primero que nos inquieta. Por encima del conocimiento de nuestro ser, nos preocupa encontrar una razón para seguir viviendo pese a muestra finitud y limitación; a pesar del mal, del dolor y del sufrimiento.

De acuerdo con SJC, el fin sobrenatural de la vida es la unión de semejanza amorosa con Dios. Y el único medio adecuado para tal fin es la 
fe sobrenatural, que Dios infunde en contemplación. Mas, a fin de disponerse favorablemente para la infusión de las virtudes teologales (fe, esperanza y caridad), que supone la infusión simultánea de los hábitos y los actos de las virtudes morales, el hombre debe hacer cuanto esté en su poder para liberarse de sus imperfecciones. Es decir, para aniquilar aquellas tendencias desordenadas de su voluntad que debe desaparecer porque impiden la unión y armonizar aquellas operaciones de sus potencias que deben permanecer.

Quien de veras desea unirse a la presencia amorosa de Dios, para corresponder al amor que desde siempre, de modo preeminente, incondicional, inmerecido y universal nos ha dispensado, está dispuesto a la negación de todo aquello que oculta la presencia interior de Dios. Cuando es auténtico, el deseo de Dios no se limita a la aparición ocasional de elevados sentimientos religiosos o inflamaciones amorosas de la voluntad que, mientras duran, inducen al individuo a las prácticas piadosas, pero tan pronto pasan, lo dejan en la misma disposición egoísta y autocentrada. El camino de perfección nada tiene que ver con la experiencia estética de lo sagrado.

La experiencia de Dios no consiste en recreaciones y gustos, ni sentimientos espirituales; sino en el seguimiento de la cruz. Quien, a raíz del encuentro con la manifestación elusiva del Amado ha quedado presa de su amor, no retrocede ante los dolores, sufrimientos, privaciones y sequedades de los procesos de purificación que tienen lugar en la noche activa y pasiva del sentido y del espíritu. Tal hombre avanza por la noche, guiado con la iluminación oscura y amorosa de la fe, que como única guía, lo impulsa a no desfallecer; a consentir al movimiento del deseo de Dios, que le permite avanzar en el camino de perfección. Lo que pone de manifiesto que el desapego y la negación surgen y están sostenidos por el amor. El desapego nace del movimiento amoroso que la presencia de dio suscita en el alma, con el propósito de atraerla hacia sí.

Ahora bien, puesto que el hombre es libre, de ello se sigue que incluso después de haber sido interpelado por el Esposo, tiene la opción de ignorar su vocación para concentrarse en la afirmación de sí mismo; en la conquista de una autonomía que lo aleja del amor divino, porque lo hace olvidar que es Dios quien sostiene su existencia.

Por otro lado está el problema de explicar cómo es que, incluso quienes, al menos en el discurso, sostienen que la salvación es la único valioso, rechazan el camino de la negación que permite ascender a la cima del monte perfección, donde mora escondida la presencia de Dios. Lo que equivale a preguntarse ¿por qué no todos los sujetos religiosos son místicos? La respuesta de SJC es tan tajante como clara: unirse a Dios es hacerse semejante al Esposo, lo que supone caminar junto con 
Él rumbo al Calvario, y padecer la más profunda noche oscura del abandono del Padre, para participar también de su resurrección. Al referirse a la participación de la sabiduría divina, que el místico alcanza al llegar al matrimonio espiritual, hasta donde su finitud se lo permite, SJC advierte que "para entrar en estas riquezas de su sabiduría la puerta es la cruz, que es angosta, y desear entrar por ella es de pocos, mas desear los deleites a que se viene por ella es de muchos" (Cruz, 1994a: canción 36, párrafo 13).

El que ama, no puede conformarse con adorar algo que no alcanza a comprender. La fe no tiene por contenido una realidad que no se entiende; sino una realidad que, al ser comprendida a la luz de la iluminación sobrenatural del entendimiento, es consciente de su limitación y, por eso mismo, sabe que mientras dure esta vida, sólo podrá comprender de modo parcial, como a través de un velo, el Misterio de Dios. De acuerdo con SJC, el fin sobrenatural de la vida es el conocimiento amoroso de Dios, que transforma al hombre en semejanza del Esposo, puesto que en el contexto de la mística conocer es ser. De donde se sigue que el alma que "de veras desea sabiduría divina desea primero el padecer para entrar en ella en la espesura de la cruz" (Cruz, 1994a: canción 36, párrafo 12).

La pregunta con la que quisiera cerrar esta meditación es: ¿̇no hemos olvidado que la cruz no es sólo un símbolo de la fe sino el recuerdo de que fue en ese acontecimiento insólito donde se mostró la esencia del amor-ágape? ¿No hará falta, para revitalizar la experiencia cristiana de la fe, hacer una reelaboración de la teología de la cruz, que vuelva a poner en el centro la importancia de la negación? Tal vez, el riesgo sea que todos aquellos que acuden a la religión para buscar en ella una experiencia placentera de Dios, que hacen de la religión una estética, caigan en la cuenta de que la cura a sus padecimientos está en otro lado. Pero, ¿no es cierto, acaso que el sentido de la fe cristiana es la imitación de Cristo Crucificado y Resucitado? ¿Es posible hacer la experiencia de la resurrección sin haber transitado por la noche oscura de la que habla SJC?

\section{REFERENCIAS}

-Agustín, San (2011). Confesiones. Madrid: Ediciones Mestas.

-Albaní, A. \& Astrua, M. (1992). San Juan de la Cru\%. Introducción a su doctrina espiritual. México: Cevhac.

-Cruz, San Juan de la (1994a). Cántico Espiritual B. En San Juan de la Cruz, Obras Completas. Madrid: Biblioteca de Autores Cristianos.

-Cruz, San Juan de la (1994b). Llama de amor viva B. En San Juan de la Cruz, Obras Completas. Madrid: Biblioteca de Autores Cristianos. 
-Cruz, San Juan de la (1994c). Noche Oscura. En San Juan de la Cruz, Obras Completas. Madrid: Biblioteca de Autores Cristianos.

-Cruz, San Juan de la (1994d). Subida del Monte Carmelo. En San Juan de la Cruz, Obras Completas. Madrid: Biblioteca de Autores Cristianos.

-González, L. (2012). Hacia una fenomenología del Cántico Espiritual B. ILU. Revista de Ciencias de las Religiones (17), 59-76.

-Graeff, H. (1970). Historia de la mistica. Barcelona: Biblioteca Herder.

-Haas, A. (2009). Viento de lo absoluto ¿Existe una sabiduría mistica de la posmodernidad?. Madrid: Siruela.

-Kiwka, M. (2004). Las estructuras básicas del ser humano en el pensamiento de San Juan de la Cruz. Revista San Juan de la Cruz, XX (33), 5-78.

-Martín, J. (2009). Hacia una fenomenología de la experiencia de Dios. En P. Cebollada (comp.), Experiencia y misterio de Dios. Congreso internacional en el 25 aniversario del Instituto Universitario de Espiritualidad de la Universidad Pontificia de Comillas (págs. 65-92). Madrid: Universidad Pontificia de Comillas.

-Molina, A. (1991). El dolor sufriente en la vida y escritos de San Juan de la Cruz. Seminario Médico (44), 13-43.

-Pérez, A. (2002). El mundo como creación. Ensayo de filosofía teológica. Madrid: Ediciones Encuentro.

-Ross, S. (2007). La experiencia mistica en mitad de la vida. Madrid: Editorial de Espiritualidad.

-Ruiz, F. (1968). Introducción a San Juan de la Cruz. El hombre, los escritos, el sistema. Madrid: Biblioteca de Autores Cristianos.

-Sesboüé, B. (1997). Redención y salvación en Jesucristo. En O. González, Salvador del Mundo. Historia y actualidad de Jesucristo. Cristología Fundamental (págs. 113-132). Salamanca: Secretariado Trinitario.

Sumario: Introducción; 1. El poder creador del amor divino: origen de la existencia; 2. La unión de semejanza amorosa con el Esposo Cristo: fin sobrenatural de la existencia; 3. La mística: camino de plenitud; Conclusión; Referencias. 